\title{
Accummulation Effects of Chemical and Organic Fertilizers on Tetranychus urticae koch and Phytoseiulus persimilis A.-H. under Laboratory Conditions
}

\author{
M. N. Nour El-Deen and M. M. El-Sebaay \\ Plant Protection Institute, A.R.C., Dokki, Giza, Egypt.
}

\begin{abstract}
The toxicity effects of treating the four chemical and organic fertilizers 'Animal Manure, Animal Manure + Neem Manure, Potassen and Novatreen' compared with the recommended compound 'Ortus' were tested on the two-spotted spider mite, Tetranychus urticae Koch and its predatory mite, Phytoseiulus persimilis A.-H. under laboratory conditions. The accumulation mortality percentages of T. urticae and P. persimilis were recorded after 24, 48 and 72 hours from treatment, increased gradually with increasing time of the five aforementioned tested. Comparing between the effects of the five tested compounds on the immatures, adult females and eggs of $T$. urticae and its toxicity on the predator $P$. persimilis after 24,48 and 72 hours from treatment were compared. Ortus recorded the highest effect, followed by Potassen and Animal Manure + Neem Manure; while Animal Manure and Novatreen gave the least effect. $\mathrm{LT}_{50}$, $\mathrm{LT}_{90}$ and slop values of T. urticae and its predatory P. Persimilis were calculated, and can be concluded that P. Persimilis gave more tolerance against the five tested compounds than T. urticae.
\end{abstract}

Key words: Tetranychus urticae, Phytoseiulus persimilis, Chemical, Organic, Fertilizer.

\section{INTRODUCTION}

The two spotted-spider mite, Tetranychus urticae Koch (Acari: Tetranychidae) is a major economic pest attacking several kinds of field crops and vegetables especially cotton, strawberry, cucumber and cantaloupe in Egypt. The appearance of plant infectedwith mites appears on the plant parts especially leaves. Its damage results from, feeding and removal of plant juices that causes plants to have small red or bronzed leaves that may dry and fall off due to heavy infestations. It affects the quality and quantity of the yield crops. Combining tactics involving reduced-risk pesticides and selective releases of predatory mites may yield more acceptable control of the two-spotted spider mite; while maintaining predatory mite populations in the field (Rhodes et al., 2006), The predatory mite Phytoseiulus persimilis (Athias-Henriot) is an economically important species in integrated pest management and biological control of spider mites in many countries throughout the world,so It is important to know if acaricides have adverse undesirable effects on the predatory mites (Nadimi et al., 2008).Several acaricides including flufenoxuron, fenpyroximate and abamectin are currently used in Egypt. However, the side effects of the acaricides to key spider mite predator including $P$. persimilis are unidentified Abd-Elhady and Heikal (2011). In many cases, the combined use of chemical and biological control might provide the best approach for both managing pest populations and minimizing selection for resistance (Gentz et al., 2010). Fertilizers are usually added to the soil; but it is known that the plants can absorb nutrition which is applied directly into the leaves. The possibility of killing other insects by plant nutrient supplements is to be explored further (Sung-Ching, 1995). Insect pests of the plant that received foliar spray of compost extracts were minimal compared with nonfertilized plants and those that received soil incorporated NPK fertilizer. This suggests a dual role of this compost extract foliar sprays as source of nutrients and materials for controlling insect pests (Akanbi, 2007).

The present work aims to study the accumulation toxicity effects of chemical and organic fertilizers on the two-spotted spider mite, Tetranychus urticae Koch and its predatory mite, Phytoseiulus persimilis A.-H. under laboratory conditions.

\section{MATERIALS AND METHODS}

\section{Mites tested culture}

The original populations of $T$. urticae and its predator were obtained from stock cultures maintained in two separated greenhouses belonging to Plant Protection Research Institute at Dokki district (Giza governorate) and reared under laboratory conditions at $25 \pm 2{ }^{\circ} \mathrm{C}$ and $65 \pm 5 \%$ R.H. on kidney bean plants, Phaseolus vulgaris (L.).The predacious mite Phytoseiulus persimilis Athias-Henriot was reared in plastic boxes $(26 \times 15 \times 10 \mathrm{~cm})$, a cotton pad was put in the middle of each box, provided with water as a barrier to prevent predatory mite individuals from escaping in addition to a tangle foot strip at the box edges. Highly infested bean leaves with $T$. urticae were provided as food sources to the predacious mite in the laboratory. Individuals of $P$. persimilis (Athias-Henriot) were obtained from its mass rearing on spider mites T. urticae Koch on bean plants in a greenhouse $60 \times 9 \mathrm{~m}^{2}$ about $540 \mathrm{~m}^{2}$ (ElHalawany et. al.,2000 ; Heikal and Ibrahim, 2002). 


\section{Tested compounds:}

The compounds used in the present experiments were:

- Ortus $5 \%$.

- Animal Manure 10\% (AM).

- Animal Manure 10\% + Neem Manure 10\% (ANM).

- Potsasen foliar fertilizer spray $(0.16 \%)$ contains K $30 \%+$ P $8 \%$.

- Novatreen foliar fertilizer spray $(0.33 \%)$ contains $\mathrm{N} 8 \%+\mathrm{P} 5 \%+\mathrm{K} 5 \%$ + cleat Fe $0.4 \%$ + cleat $\mathrm{Zn}$ $0.3 \%+$ Mn $0.3 \%+$ B $0.05+$ Mo $0.3 \%$.

- Control with water.

\section{Method of application}

The effect of different compounds were evaluated under laboratory conditions. All treatments of the toxic effect of the tested materials on the two-spotted spider mite, T. urticae Koch and its predatory mite, $P$. persimilis A.-H..All were occurred by leaf disc dip technique according to Siegler (1947). Diluted suspensions of different concentrations of these compounds were prepared by distilled water for comparing. Discs ( $2 \mathrm{~cm}$ diam.) of kidney bean leaves were then dipped in each concentration and others in distilled water (control) for, 5 seconds and left to dry.

\section{T. urticae mortality}

Twenty of each immature stages, adult females and eggs of the two spotted spider mites were transferred to the lower surface to each disc of kidney bean leaf ( 20 individuals/leaf disc) treated previously.

\section{$P$. persimilis mortality}

Twenty adult females and eggs of the predacious mite $P$. persimiliswere transferred to each kidney bean leaf disc ( $5 \mathrm{~cm}$ in diameter) treated previously, using a brush. The discs were placed on a moist filter paper, rested on a moist cotton wool pads in Petri dishes. A number of $T$. urticae were added as a food for $P$. persimilis. Each treatment was replicated four times. Mortality was recorded after 24, 48 and 72hours post treatments.

\section{Statistical analysis}

The natural mortality was corrected according to Abbott's formula (1925).The corrected percent mortalities were statistically compounded according Finney (1971) and plotted on probit analysis paper. The tested compounds were compared for its efficacy on the mite and its predator according to their $\mathrm{LC}_{50}$, $\mathrm{LC}_{90}$ and slopes of the toxicity lines. Toxicity index of tested compounds were determined according to Sun (1950).

\section{RESULTS AND DISCUSSION}

\section{Accumulation toxicity of chemical and organic fertilizers on $T$. urticae basis on Percent mortality}

According to the obtained data (Table 1), different mortality percentages were recorded, when immature stages of $T$. urticae were treated with different chemical and organic fertilizers'Animal Manure, Animal Manure + Neem Manure, Potassen and Novatreen' compared with recommended compound 'Ortus'; the mortality percentages were 50.0, 33.3, 36.7 and $36.7 \%$ after 24 hours, respectively ; while was 70.0 , when treated with Ortus. The accumulation percent reduction after 48 hours were 73.30, 64.13, 64.70 and $62.27 \%$, respectively; while reached $85.57 \%$ in case of Ortus against T. urticae immature stages. Accumulation effects of these compounds after 72 hours reached $76.6,86.76,91.17$ and $62.27 \%$ reduction, respectively compared with Ortus $(94.47 \%)$.

On the other hand, females of $T$. urticae treated with different chemical and organic fertilizers'Animal Manure, Animal Manure + Neem Manure, Potassen and Novatreen comparing with recommended compound 'Ortus' gave mortality percentages reached 43.30, 20.0, 26.67 and $40.0 \%$ after 24 hours, respectively; while reached $60.0 \%$ when treated with Ortus. The accumulation percent reductions after 48 hours were $63.0,50.0,32.24$ and $58.90 \%$, respectively; while reached $74.47 \%$ in case Ortus compound against adult females of T. urticae, whereas, accumulation effects of these compounds after 72 hours reached $73.3,80.0,81.14$ and $71.13 \%$ reduction, respectively comparing with Ortus $(87.80 \%)$.

Against T. urticae egg stage 'Animal Manure, Animal Manure + Neem Manure, Potassen and Novatreen' compared with recommended compound 'Ortus' gave little effects against eggs; the mortality percentages were 5.0, 6.7, 1.7 and $5.0 \%$ after 24 hours, respectively; while reached $30.0 \%$ when treated with Ortus. The accumulation percent reduction after 48 hours were $31.7,27.0,31.7$ and $15.0 \%$, respectively; while reached $55.0 \%$ in case of Ortus compound against eggs of T. urticae; whereas, accumulation effects of these compounds after 72 hours reached 55.03, 61.67, 53.36 and $35.0 \%$ reduction, respectively compared with $85.0 \%$ for Ortus.

The obtained results agree with those obtained by El-Khateeb et al. (2004) who evaluated the effectiveness of some new safe chemicals against the moving stages of $T$. urticae. They found that (Dipel 2X (Bacillus thuringiensis) at $50 \mathrm{~g}, \mathrm{~S}-1283$ at $150 \mathrm{ml}$ ) and Three Targets (plant oils, fatty acids and essential micronutrients) at $500 \mathrm{ml} / 100$ litters of water gave percent reduction $74.98,75.82 \%, 73.70$, 74.86 and $74.53 \%$, respectively. Three Targets at the lowest rate of $250 \mathrm{ml} / 100$ litters water were the least effective material with $67.9,68.03$ and $68.80 \%$ 
Table (1): Accumulation mortality percentages of different chemical and organic fertilizerson the two-spotted spider mite, Tetranychus urticae Koch under laboratory conditions.

\begin{tabular}{|c|c|c|c|c|c|c|c|}
\hline \multirow{3}{*}{ Material } & \multirow{3}{*}{ Stage } & \multicolumn{6}{|c|}{ Periods after treatment } \\
\hline & & \multicolumn{2}{|c|}{$24 \mathrm{~h}$} & \multicolumn{2}{|c|}{$48 \mathrm{~h}$} & \multicolumn{2}{|c|}{$72 \mathrm{~h}$} \\
\hline & & Mean No. & \%Mortality & Mean No. & \%Mortality & Mean No. & \%Mortality \\
\hline \multirow{3}{*}{ Ortus } & Immatures & 7.00 & 70.00 & 8.67 & 85.57 & 9.67 & 94.47 \\
\hline & Adult & 6.00 & 60.00 & 7.57 & 74.47 & 9.27 & 87.80 \\
\hline & Egg & 3.0 & 30.0 & 8.0 & 55.0 & 15.33 & 85.00 \\
\hline \multirow{3}{*}{$\mathrm{AM}$} & Immatures & 5.00 & 50.00 & 2.33 & 73.30 & 8.33 & 76.60 \\
\hline & Adult & 4.33 & 43.30 & 6.33 & 63.00 & 7.66 & 73.30 \\
\hline & Egg & 0.3 & 5.0 & 5.6 & 31.7 & 11.33 & 55.03 \\
\hline \multirow{3}{*}{ ANM } & Immatures & 3.33 & 33.30 & 6.33 & 64.13 & 9.00 & 86.76 \\
\hline & Adult & 2.00 & 20.00 & 5.33 & 50.00 & 8.66 & 80.00 \\
\hline & Egg & 1.3 & 6.7 & 6.0 & 27.0 & 16.00 & 61.67 \\
\hline \multirow{3}{*}{ Potassen } & Immatures & 3.67 & 36.70 & 7.0 & 64.70 & 9.67 & 91.17 \\
\hline & Adult & 2.67 & 26.67 & 5.34 & 32.24 & 8.34 & 81.14 \\
\hline & Egg & 0.3 & 1.7 & 6.3 & 31.7 & 11.67 & 53.36 \\
\hline \multirow{3}{*}{ Novatreen } & Immatures & 3.67 & 36.70 & 7.00 & 62.27 & 7.67 & 62.27 \\
\hline & Adult & 4.00 & 40.00 & 6.00 & 58.90 & 7.33 & 71.13 \\
\hline & Egg & 1.0 & 5.0 & 3.0 & 15.0 & 8.00 & 35.00 \\
\hline \multirow{3}{*}{ Control } & Immatures & 0.00 & - & 0.11 & - & 0.22 & - \\
\hline & Adult & 0.00 & - & 0.11 & - & 0.22 & - \\
\hline & Egg & 0.00 & - & 0.0 & 0.00 & 1.00 & - \\
\hline
\end{tabular}
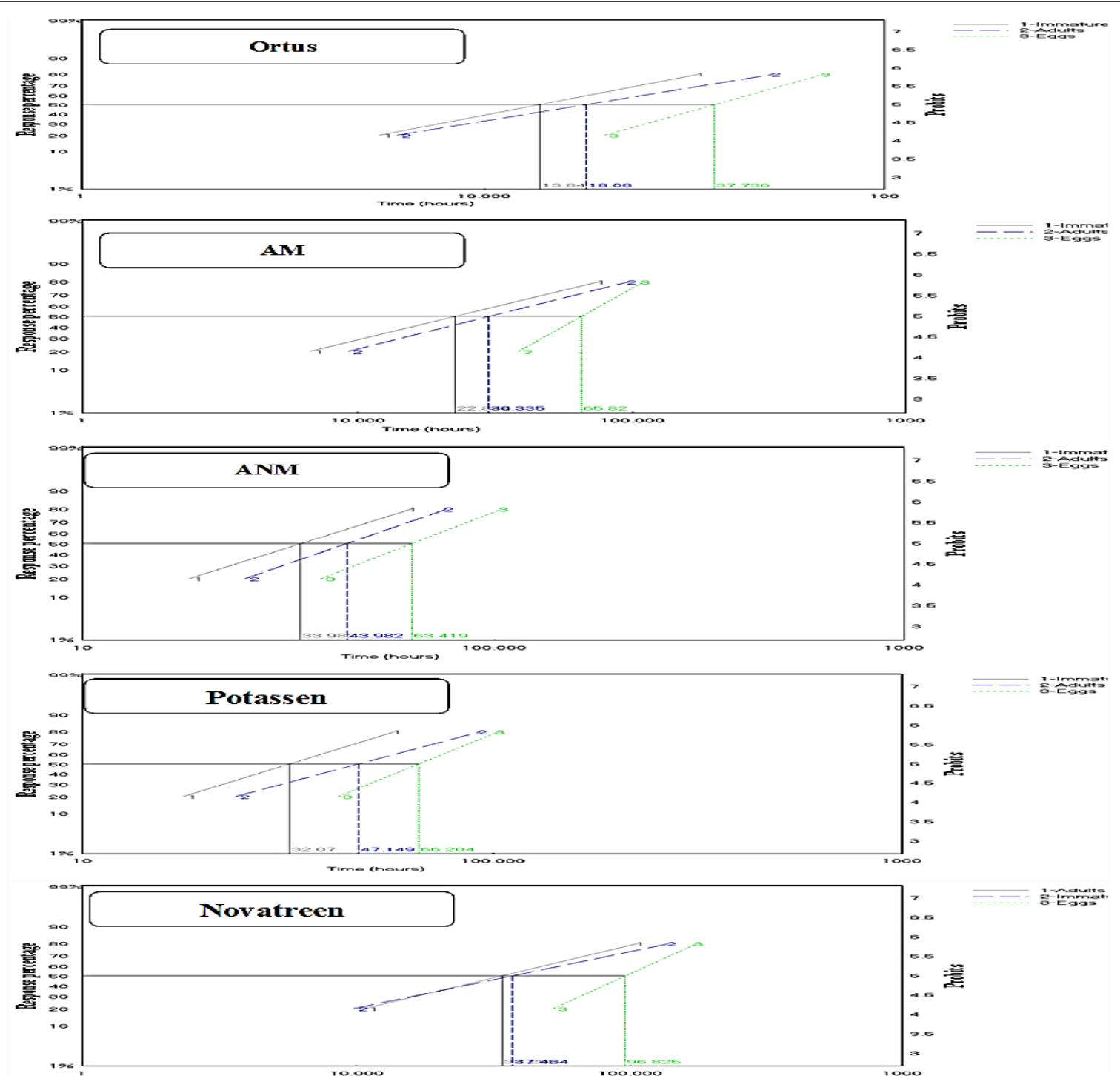

Fig. (1): LT values of different chemical and organic fertilizerson Tetranychus urticae at different intervals under laboratory conditions. 
Table (2): LT values and slopes of different chemical and organic fertilizerson the two-spotted spider mite, Tetranychus urticae Koch and the predatory mite, Phytoseiulus persimilis A.-H. after different intervals under laboratory conditions.

\begin{tabular}{|c|c|c|c|c|c|c|c|c|c|}
\hline \multirow{3}{*}{ Compound } & \multicolumn{9}{|c|}{ Tetranychus urticae } \\
\hline & \multicolumn{3}{|c|}{ Immatures } & \multicolumn{3}{|c|}{ Adults } & \multicolumn{3}{|c|}{ Eggs } \\
\hline & Slope & $\mathrm{LT}_{50}$ & $\mathrm{LT}_{90}$ & Slope & $\mathrm{LT}_{50}$ & $\mathrm{LT}_{90}$ & Slope & $\mathrm{LT}_{50}$ & $\mathrm{LT}_{90}$ \\
\hline Ortus & 2.1079 & 13.840 & 56.123 & 1.7927 & 18.080 & 93.774 & 3.0723 & 37.736 & 98.605 \\
\hline $\mathrm{AM}$ & 1.6004 & 22.844 & 144.397 & 1.6401 & 30.335 & 183.388 & 3.6871 & 65.820 & 146.536 \\
\hline ANM & 3.1179 & 33.982 & 87.560 & 3.4394 & 43.982 & 103.727 & 3.8349 & 63.419 & 136.903 \\
\hline Potassen & 3.2497 & 32.070 & 79.520 & 2.8200 & 47.149 & 134.258 & 4.3181 & 66.204 & 131.124 \\
\hline Novatreen & 1.4543 & 37.464 & 285.018 & 1.6826 & 34.292 & 198.088 & 3.2027 & 96.825 & 243.302 \\
\hline
\end{tabular}

Table (3): Accumulation mortality percentages of different chemical and organic fertilizers on the predatory mite, Phytoseiulus persimilis A.-H.under laboratory conditions.

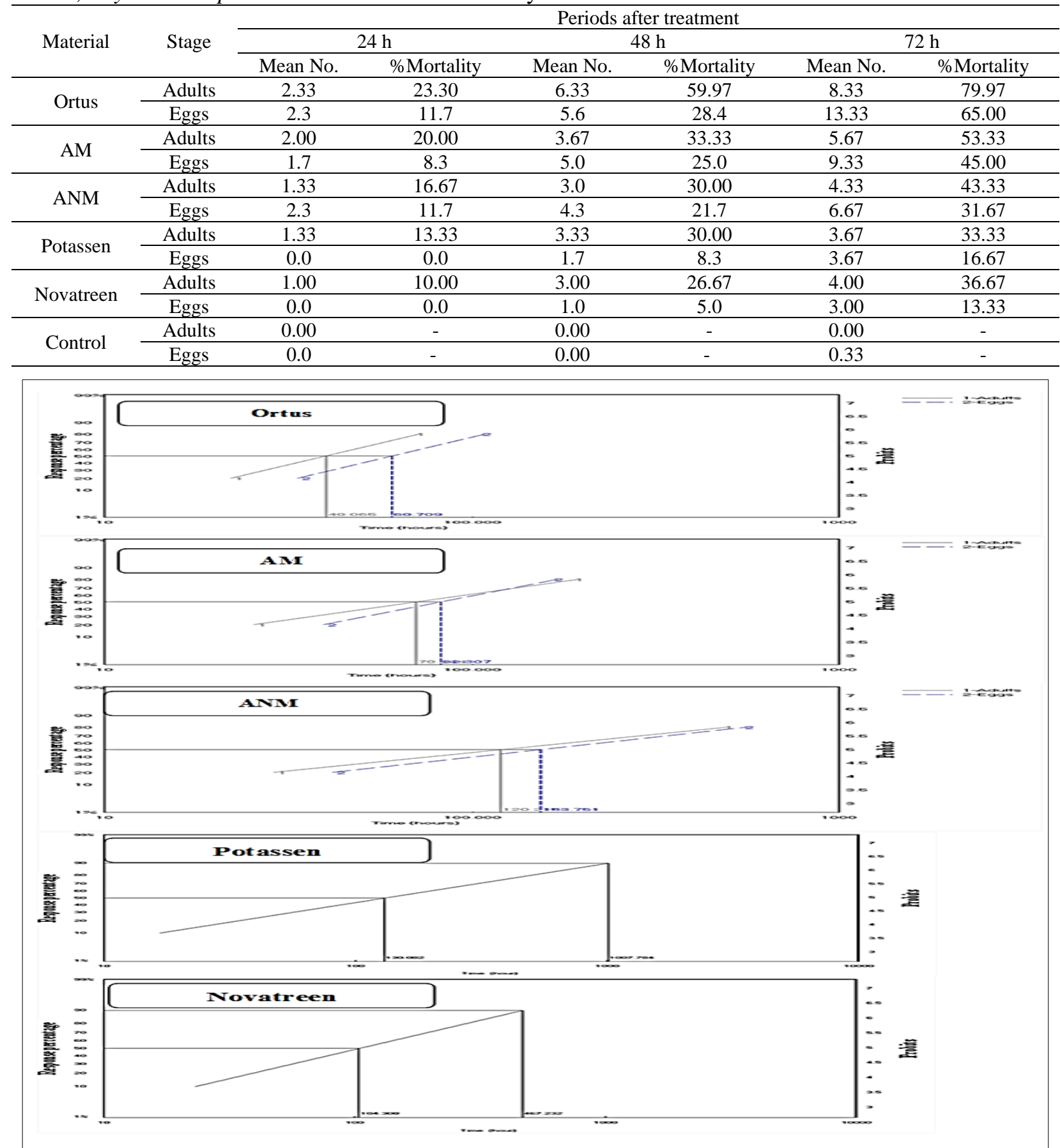

Fig. (2): LT values of different chemical and organic fertilizers on the predatory mite, Phytoseiulus persimilis A.-H. at different intervals under laboratory conditions. 
reduction (Table1).

\section{Lethal time values}

The recorded values of $\mathrm{LT}_{50}$ and $\mathrm{LT}_{90}$ represented in Table (2) and illustrated in Fig. (1) showed the lethal time of immatures, adult females and eggs of T. urticae under laboratory conditions to the tested compounds after 72 hours.

Table (2) and Fig. (1)indicated that, the corresponding $\mathrm{LT}_{50}$ values of $T$. urticae immatures after 72 hours when treated with some chemical and organic fertilizers'Animal Manure, Animal Manure + Neem Manure, Potassen and Novatreen' compared with the recommended compound 'Ortus'were 22.844, 33.982, 32.070, 37.464 and 13.840 and the corresponding $\mathrm{LT}_{90}$ values were 144.397, 87.560, 79.520, 285.018 and 56.123hours, respectively.

The slope of line is useful to known the homogeneity of different stages (immatures, adult females and eggs) of $T$. urticae, which reared under laboratory conditions and response to different compounds.

The slope of T. urticae immatures were 1.6004, 3.1179, 3.2497, 1.4543 and 2.1079 after 72 hours when treated with Animal Manure, Animal Manure + Neem Manure, Potassen and Novatreen compared with 'Ortus', respectively.

For adult females of $T$. urticae, the corresponding $\mathrm{LT}_{50}$ values after 72 hours of treated compounds were 30.335, 43.982, 47.149, 34.292 and 18.080 hours, respectively, whereas, $\mathrm{LT}_{90}$ were $183.388,103.727$, 134.258, 198.088 and 93.774 hours, respectively after treated with the aforementioned fertilizers, respectively.

Table (2) and Fig. (1)show that the slope of adult females of T. urticae were 1.6401, 3.4394, 2.8200, 1.6826 and 1.7927 after 72 hours when treated with Animal Manure, Animal Manure + Neem Manure, Potassen and Novatreen compared with recommended compound 'Ortus', respectively.

For $T$. urticae eggs, the corresponding $\mathrm{LT}_{50}$ values after 72 hours of treated compounds were 65.820, $63.419,66.204,96.825$ and 37.736 hours, respectively, whereas, $\mathrm{LT}_{90}$ were $146.536,136.903$, 131.124, 243.302 and 98.605 hours, respectively after treated with Animal Manure, Animal Manure + Neem Manure, Potassen and Novatreen' compared with Ortus.

Table (2) and Fig. (1) show that the slope of $T$. urticae eggs were $3.6871,3.8349,4.3181,3.2027$ and 3.0723 after 72 hours when treated with Animal Manure, Animal Manure + Neem Manure, Potassen and Novatreen compared with Ortus, respectively.
Accumulation toxicity of different chemical and organic fertilizers on predatory mite, $P$. Persimilis basis on

\section{Percent mortality}

According to the obtained results in Table (3), toxicity effects were recorded when $P$. Persimilis immatures were treated with different chemical and organic fertilizers 'Animal Manure, Animal Manure + Neem Manure, Potassen and Novatreen' comparing with recommended compound 'Ortus'; the toxicity effects were 20.0,16.67, 13.33 and $10.0 \%$ after 24 hours, respectively with Animal Manure, Animal Manure + Neem Manure, Potassen and Novatreen; while was $23.3 \%$, when treated with Ortus; while the accumulation percent reduction after 48 hours were $33.33,30.0,30.0$ and $26.67 \%$, respectively; while reached to $59.97 \%$ for Ortus compound against the adults of $P$. Persimilis; whereas, accumulation effects of these compounds after 72 hours reached to 53.33, $43.33,33.33$ and $36.67 \%$ toxicity effects, respectively compared with Ortus (79.97\%).

Against eggs of $P$. Persimilis chemical and organic fertilizers'Animal Manure, Animal Manure + Neem Manure, Potassen and Novatreen' compared with recommended compound 'Ortus' gave little or no effects against eggs; Animal Manure and Animal Manure + Neem Manure gave 8.3, $11.7 \%$ toxicity effects after 24 hours, respectively; while Potassen and Novatreen didn't have any toxicity effects; while Ortus gave $23.30 \%$; whereas, the accumulation toxicity effects after 48 hours were 25.0, 21.7, 8.3 and $5.0 \%$, respectively; while reached to $28.4 \%$ for Ortus compound against eggs of $P$. persimilis, whereas, accumulation effects of these compounds after 72 hours reached to $45.0,31.67,16.67$ and $13.33 \%$ toxicity effects, respectively compared with Ortus $(65.0 \%)$.

The obtained results with are harmony with those obtained by Ismail et al. (2009) who reported that abamectin was the most effective compound on adult females of predator mite $P$. persimilis adult femal followed by Cyhalothrin and ethion. Chlorfenapyr had a moderate toxic effect; while black cumin extract and mineral oil (Nat1) were the least toxic compounds to adult females of $P$. persimilis.

\section{Lethal time values}

The recorded values of $\mathrm{LT}_{50}$ and $\mathrm{LT}_{90}$ 's represented in Table (4) and illustrated in Fig. (2) showed the lethal time of $P$. Persimilis adults and eggs under laboratory conditions to the tested compounds after 72 hours.

Data in table (4) and fig. (2) indicated that, the corresponding $\mathrm{LT}_{50}$ values of $P$. Persimilis adults stages of after 72 hours when treated with Animal Manure, Animal Manure + Neem Manure, Potassen 
Table (4): LT values and slopes of different chemical and organic fertilizerson the predatory mite, Phytoseiulus persimilis A.-H. after different intervals under laboratory conditions.

\begin{tabular}{lcccccc}
\hline \multirow{2}{*}{ Compound } & \multicolumn{5}{c}{ Phytoseiulus persimilis } \\
\cline { 2 - 7 } & \multicolumn{7}{c}{ Adults } & \multicolumn{3}{c}{ Eggs } \\
\cline { 2 - 7 } & Slope & LT $_{50}$ & LT $_{90}$ & Slope & LT $_{50}$ & LT $_{90}$ \\
\hline Ortus & 3.2821 & 40.065 & 98.457 & 3.2982 & 60.709 & 148.534 \\
\hline AM & 1.9060 & 70.544 & 331.805 & 2.6512 & 82.307 & 250.518 \\
\hline ANM & 1.3630 & 120.238 & 1047.958 & 1.4922 & 153.751 & 1110.993 \\
\hline Potassen & 1.4414 & 130.082 & 1007.784 & - & - & - \\
\hline Novatreen & 1.9680 & 104.308 & 467.232 & - & - & - \\
\hline
\end{tabular}

and Novatreen compared with 'Ortus' were 70.544 , $120.238,130.082,104.308$ and 40.065 hours after 72 hours and the corresponding $\mathrm{LT}_{90}$ values were $331.805,1047.958,1007.784,467.232$ and 98.457 hours, respectively.

The slope of line is useful to known the homogeneity of different stages (adults and eggs) of $P$. persimilis, which reared under laboratory conditions and response to different compounds.

Data in Table (4) and Fig. (2) showed that the slope of $P$. Persimilis adults were 1.9060, 1.3630, $1.4414,1.9680$ and 3.2821 after 72 hours when treated with Animal Manure, Animal Manure + Neem Manure, Potassen and Novatreen compared with recommended compound Ortus, respectively.

On the $P$. persimilis eggs, the corresponding $\mathrm{LT}_{50}$ values after 72 hours of treated compounds were 82.307, 153.751 and 60.709 hours, respectively, whereas, $\mathrm{LT}_{90}$ were $250.518,1110.993$ and 148.534 hours, respectively after treated with Animal Manure, Animal Manure + Neem Manure compared with Ortus.

Table (4) and Fig. (2) show that the slope of $P$. persimilis eggs were 2.6512, 1.4922 and 3.2982 after 72 hours when treated with Animal Manure, Animal Manure + Neem Manure comparing with recommended compound Ortus, respectively.

Thus, successive foliar sprays of plant nutrients and foliar fertilizers in aqueous solutions of extreme $\mathrm{pH}$ values, without employing toxic organic materials were found. Repeatedly applied sprays causing the $\mathrm{pH}$ changes provide an effective, cheap, and environmentally friendly way of fighting plant pests.The $\mathrm{pH}$ on the leaves after spraying gradually returns from the extreme value towards neutrality in few hours (Dimenstein and Nes, 2013).

\section{REFERENCES}

Abbott's, W. S. 1925. A methods for computing the effectiveness of an insecticide. J. Econ. Entomol., 18 (7): 265.
Abd-Elhady, H. K. and Heikal, M. M. 2011. Selective toxicity of three acaricides to the twospotted spider mite, Tetranychus urticae and predatory mite, Phytoseuilus persimilis in apple orchards. J. Entomol., 8: 574-580.

Akanbi, W. B.; Adebayo T. A.; Togun, O. A.; Adeyeye, A. S. andOlaniran, A. 2007. The use of compost extract as foliar spray nutrient source and botanical insecticide in Telfairia occidentalis. World J. Agricultural Sciences, 3(5): 642-652.

Akashe, V. B.; Indi, D. V.; Patil, A. J.; Gud, M. A. and Ghadge, S. M. 2006. Persistence and toxicity of some miticides against Tetranychus urticae Koch on rose foliage. J. Maharashtra Agric. Univ., 31 (3): 318-320.

Dimenstein, L. and Nes, Z. 2013. Foliar fertilizers for controlling pests. Patent application number: 20130130896.

El-Halawany, M. E.; Abd El-Samad, M. A. and Ebrahim H. M. 2000. Biological control of the spider mite Tetranychus urticae Koch by the phytoseiid mite Phytoseiulus persimilis (A.-H.) compared with chemical control. Bull. Ent. Soc. Egypt, Econ. Ser., 27,(63).

El-Khateeb, H. M.; Habashy, N. H. and Iskandar, A. K. F. 2004. Field evaluation of some new safe acaricides against the two-spotted spider mite, Tetranychus urticae Koch (Acari: Tetranychidae) infesting cowpea at Fayoum Governorate. Egyptian J. Agric. Res., 82(2): 619-629.

Finney, D. J. 1971. Probit analysis. Cambridge Univ. Press Cambridge, 33.

Gentz, M. C.; Murdoch, G. and King, G. F. 2010. Tandem use of selective insecticides and natural enemies for effective, reduced-risk pest management. Biol. Control, 52: 208-215.

Heikal, I. H. and Ibrahim, G.A. 2002. Mass production of the phytoseiid predator, Phytoseiulus macropilis (Acari: phytoseiidae) Egypt. J. Agric. Res., 80(3): 1173-1179.

Ismail, A. A.; Hosny, A. H. and Keratum, A. Y. 2009. Integrated mite management evaluation of some compounds against the two-spotted spider mite, Tetranychus urticae and two predators Amblyseius fallacies and Phytosiulus persimilis. J. Agric. Res. Kafrelsheikh Univ., 35(4). 
Nadimi, A.; Kamali, K.; Arbabi, M. and Abdoli, F. 2008. Side-effects of three acaricides on the predatory mite, Phytoseiulus persimilis Athias-henriot (Acari: Phytoseiidae) under laboratory conditions. Munis Entomol. Zool., 3: 556-567.

Rhodes, E. M.; Liburd, O. E.; Kelts, C.; Rondon, S. I. and Francis, R. R. 2006. Comparison of single and combination treatments of Phytoseiulus persimilis, Neoseiulus californicus and Acramite (bifenazate) for control of two spotted spider mites in strawberries. Exp. \& Applied Acarol., 39: 213225.

Siegler, E. H. 1947. Leaf disc technique for laboratory tests of acaricides. J. Econ. Entomol., 40: 441-442.

Sun, Y. P. 1950.Toxicity index an improved method of comparing the relative toxicity of insecticides. J. Econ. Entomol., 43: 45-53.

Sung-Ching, H. 1995. Technology for Sustainable Agriculture in Taiwan. Committee of international technical cooperation, Taiwan ROC: 10-12. 